\title{
Source process for complex fault system of the 2007 Chuetsu-oki, Niigata, Japan, earthquake
}

\author{
Takeshi Nakamura $^{1}$, Yasushi Ishihara ${ }^{1}$, Yoshiko Yamanaka ${ }^{2}$, and Yoshiyuki Kaneda ${ }^{1}$ \\ ${ }^{1}$ Japan Agency for Marine-Earth Science and Technology, 3173-25 Showa-machi, Kanazawa-ku, Yokohama 236-0001, Japan \\ ${ }^{2}$ Research Center for Seismology and Volcanology, Nagoya University, Furo-cho, Chikusa-ku, Nagoya 464-8602, Japan
}

(Received June 5, 2008; Revised August 27, 2008; Accepted September 5, 2008; Online published February 18, 2009)

\begin{abstract}
The 2007 Chuetsu-oki earthquake occurred in the offshore area of Niigata Prefecture, central Japan, on 16 July 2007. The aftershock distribution shows two fault planes, dipping to the northwest and southeast, respectively, which form a cross-sectional "V" pattern. We analyze the kinematic source process for the two fault planes consistent with the aftershock distribution using teleseismic body waveform data. Our results indicate that the mainshock initiated rupture on both faults northeast of their intersection and that the rupture propagated unilaterally southwestward along the southeast-dipping fault. The maximum slip is $1.6 \mathrm{~m}$ on the southeastdipping fault, and the seismic moments of northwest- and southeast-dipping faults are $8.0 \times 10^{17} \mathrm{~N} \mathrm{~m}\left(M_{\mathrm{w}} 5.9\right)$ and $7.5 \times 10^{18} \mathrm{~N} \mathrm{~m}\left(M_{\mathrm{w}} 6.5\right)$, respectively. The forward modeling of geodetic displacement from the obtained fault model is consistent with the GPS and InSAR measurements. Successive conjugate reverse faults around the source region are identified from the reflection seismic sections. We presume that stress changes and complicated structures in property and geometry around the source region are the dominant causal factors for generating the complexity of coseismic fault system.
\end{abstract}

Key words: Chuetsu-oki earthquake, asperity, source process, conjugate fault, teleseismic wave, GPS, SAR, stress change.

\section{Introduction}

The 2007 Chuetsu-oki earthquake occurred in the offshore area of Niigata Prefecture, central Japan, on 16 July 2007. In all, 14 people were killed and more than 2000 people were injured. The earthquake also damaged many houses and the infrastructure, and at the Kashiwazaki power plant, the world's largest nuclear power plant, a maximum horizontal acceleration of 2058 gals $(2.1 \mathrm{~g})$ was recorded.

The source area is characterized by a relatively higher level of seismicity, where large earthquakes of the $M$ 6-7 class have historically occurred with frequency. On 23 October 2004, the 2004 Chuetsu earthquake $\left(M_{\mathrm{w}} 6.6\right)$ occurred about $40 \mathrm{~km}$ south of the 2007 mainshock. The continuous GPS measurements show a large strain rate around these source areas due to the motion of plates surrounding the Japanese Islands. Sagiya et al. (2000) have proposed a strong deformation belt from the Niigata to Kobe area, called the Niigata-Kobe Tectonic Zone (NKTZ), along the Japan Sea coast based on an anlysis of GPS network (GEONET) data. In the NKTZ, a number of quaternary active faults are concentrated. Although the main fault trace has not been found around the source region of the 2007 earthquake, the mainshock occurred in the upper crust with a steeply dipping reverse fault mechanism under the northwest-southeast compression, which is quite usual in the northern part of the NKTZ, implying a relationship be-

Copyright (c) The Society of Geomagnetism and Earth, Planetary and Space Sciences (SGEPSS); The Seismological Society of Japan; The Volcanological Society of Japan; The Geodetic Society of Japan; The Japanese Society for Planetary Sciences; TERRAPUB tween the seismic source and the regional deformation in the NKTZ.

The aftershock distribution over a period of a couple of days shows two fault planes, dipping to the northwest and southeast, respectively, which form a cross-sectional "V" (e.g., Yukutake et al., 2008). The fault system with multifault planes with nearly conjugate geometry is not an unusual feature and has been studied in some events, 1980 Irpinia, Italy, by Bernard and Zollo (1989), 1982 North Yemen by Langer et al. (1987), 1982 Miramichi, Canada, by Wetmiller et al. (1984) and Choy et al. (1983), 1988 Tennant Creek, Australia, by Bowman et al. (1990), and 1990 Nooksack Forks, USA, by Qamar and Zollweg (1990). Recent studies (e.g., Choy and Bowman, 1990; Bowman, 1991; Payne et al., 2004) discuss not only the fault geometry but also the stress regime around the source region. In Japan, these fault systems have been found in the 1997 Northwestern Kagoshima earthquake (e.g., Miyamachi et al., 1999) and the 2004 Chuetsu earthquake (e.g., Sakai et al., 2005; Shibutani et al., 2005).

The aftershock distribution reveals the source fault structure and may help us understand source mechanisms of the mainshock. However, we can not follow a time history of faulting during rupturing from only the spatial analysis of the distribution using the limited number of events, and it is difficult to understand the relation of the fault system with the source characteristics, such as heterogeneous fault slip in a fault plane.

In this paper, we investigate the slip distribution by applying waveform inversion for the fault models of two op- 
(a)
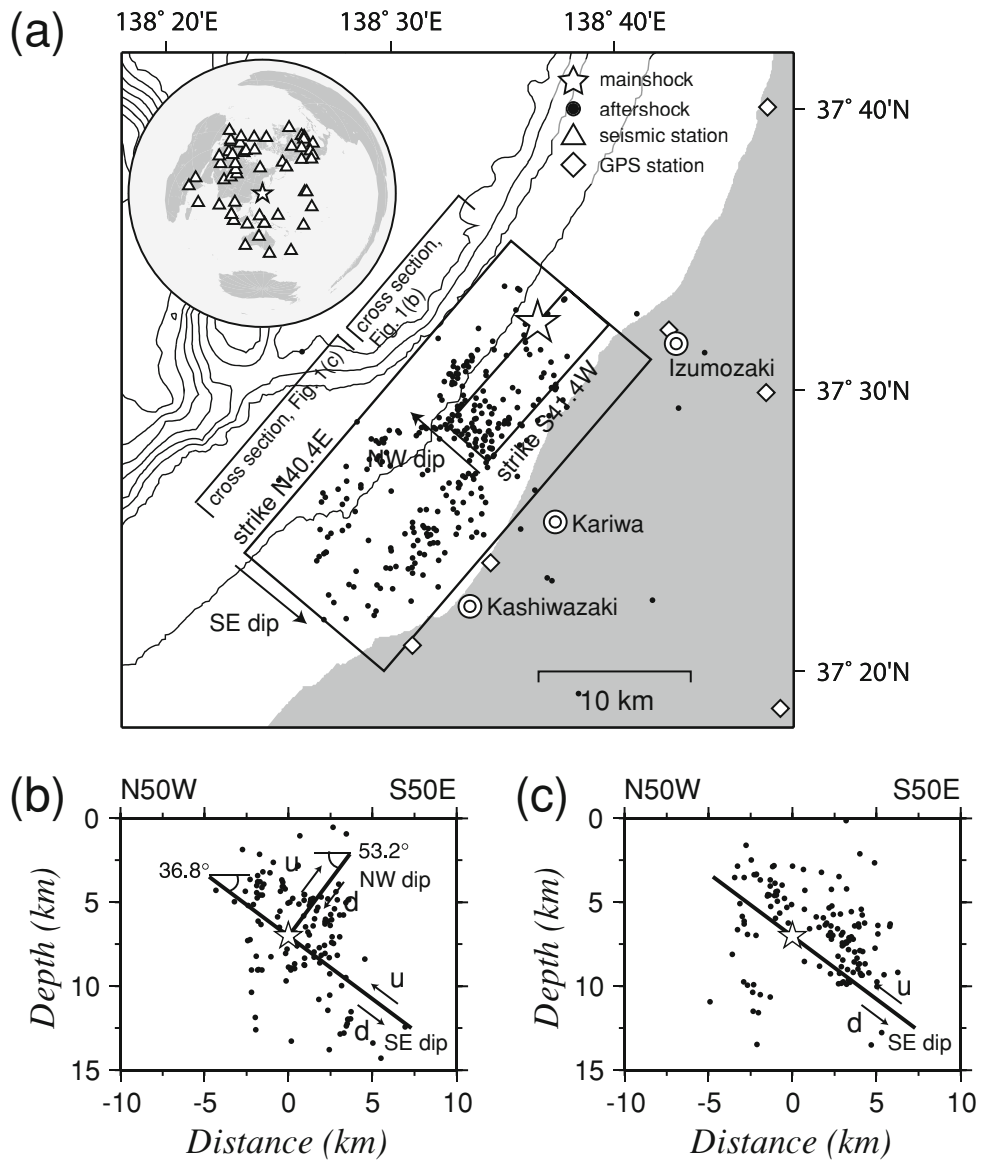

$\mathrm{u}$ : upward movement $\mathrm{d}$ : downward movement

Fig. 1. Fault models (rectangles) used in this study. (a) Epicenters of the mainshock (white star) and the aftershocks (black dots) before the largest aftershock (Yukutake et al., 2008). The white diamonds and the double circles indicate GPS stations used in comparison with synthetic crustal deformation in Fig. 4 and main cities and towns around the source area, respectively. Bathymetric lines are drawn every $100 \mathrm{~m}$. The broadband seismic stations used in this study are shown by triangles. (b) Schematic illustration of the fault geometries in the cross section projected on the NW-SE direction in the northeastern part and (c) the southwestern part.

positely dipping thrust faults (oriented in a conjugate manner). We show that the 2007 mainshock ruptured near the northeastern ends of the two faults and the main energy release occurred along the southeast-dipping fault associated with rupturing in the northwest-dipping fault.

\section{Data and Analysis}

We apply the waveform inversion of Kikuchi and Kanamori (2003) using teleseismic body waveform data for the 2007 Chuetsu-oki earthquake. The waveform inversion deconvolves complex waveforms into subevents and determines the location of asperities and the spatial distribution of slip directions and seismic moments at the mainshock, which then provides us with an informative clue on the heterogeneous source properties in a fault plane.

The teleseismic waveform data were retrieved from the IRIS and the Ocean Hemisphere Network Project (OHP) data center. We use 50 stations with epicentral distances between $30^{\circ}$ and $100^{\circ}$ for $P$-wave data. The broadband original data are integrated into ground displacement and band-pass filtered in the frequency band $0.002-1 \mathrm{~Hz}$. We use a one-dimensional (1D) velocity structure referring to the results of the seismic reflection surveys by No et al. (2008). The results of Yukutake et al. (2008) obtained by using station correction and the double-difference method, are adopted as a reference epicenter. In the faults, we assume that a maximum rupture front velocity is $3.0 \mathrm{~km} / \mathrm{s}$, and four point sources are placed at each subfault. The nonnegative least-squares method (Lawson and Hanson, 1974) is employed for constraining the rake angle.

For fault geometries, we use the waveform inversion approach of Kikuchi and Kanamori (1991) to estimate the optimal focal mechanism of the mainshock. We estimate a reverse mechanism with the preferred fault plane of: strike $\mathrm{N} 40.4^{\circ} \mathrm{E}$, dip $36.8^{\circ}$, slip $89.2^{\circ}$. Taking into account the aftershock distribution nearly conjugate to the preferred fault plane in the northeastern region, we determine the conjugate fault plane of: $\mathrm{S} 41.4^{\circ} \mathrm{W}$, dip $53.2^{\circ}$, slip $90.6^{\circ}$ for the northwest-dipping fault (Fig. 1). Each fault size (length and down-dip width) is constructed taking into consideration the aftershock distribution of Yukutake et al. (2008).

\section{Results}

The inversion results of the 2007 Chuetsu-oki earthquake indicate that the mainshock is composed of two subevents (Fig. 2) with seismic moments of $8.0 \times 10^{17} \mathrm{~N} \mathrm{~m}\left(M_{\mathrm{w}} 5.9\right)$ and $7.5 \times 10^{18} \mathrm{~N} \mathrm{~m}\left(M_{\mathrm{w}} 6.5\right)$, which together add up to a total of $8.3 \times 10^{18} \mathrm{~N} \mathrm{~m}\left(M_{\mathrm{w}} 6.6\right)$. Assuming a rigidity of 

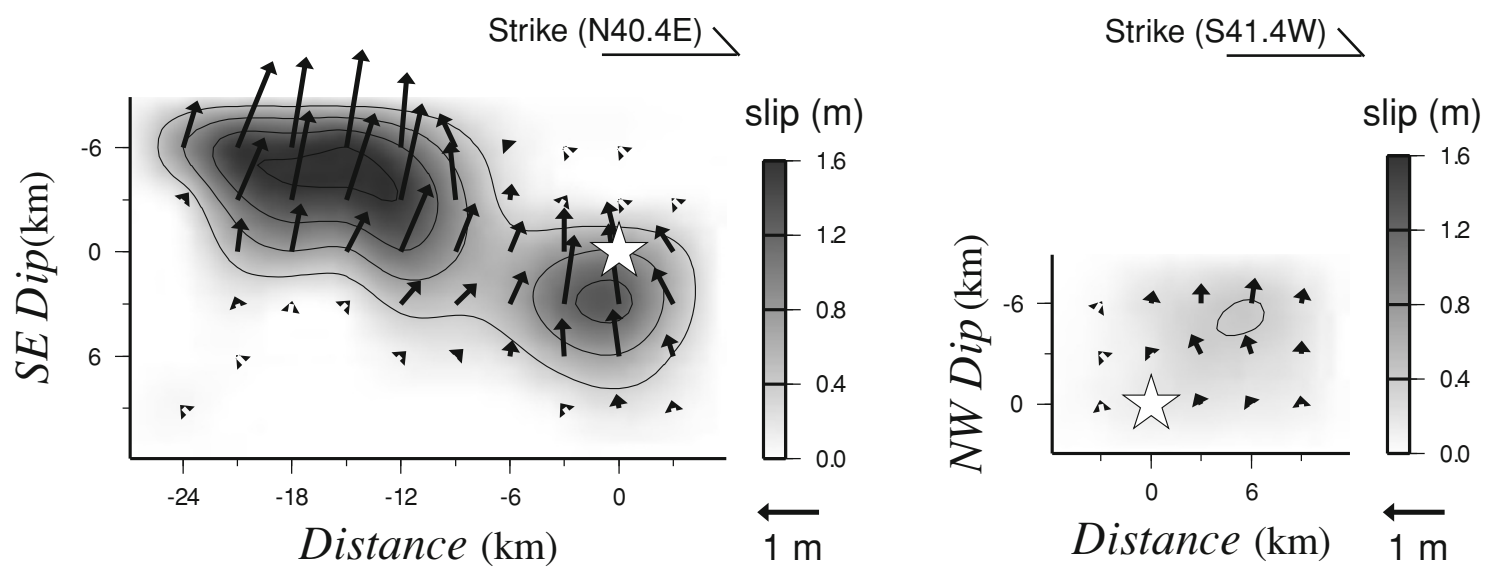

Fig. 2. Slip distribution inferred from the waveform inversion. The white star indicates the initial break point. The origin point in the vertical axis is at the depth of $7 \mathrm{~km}$ corresponding to the initial break point.

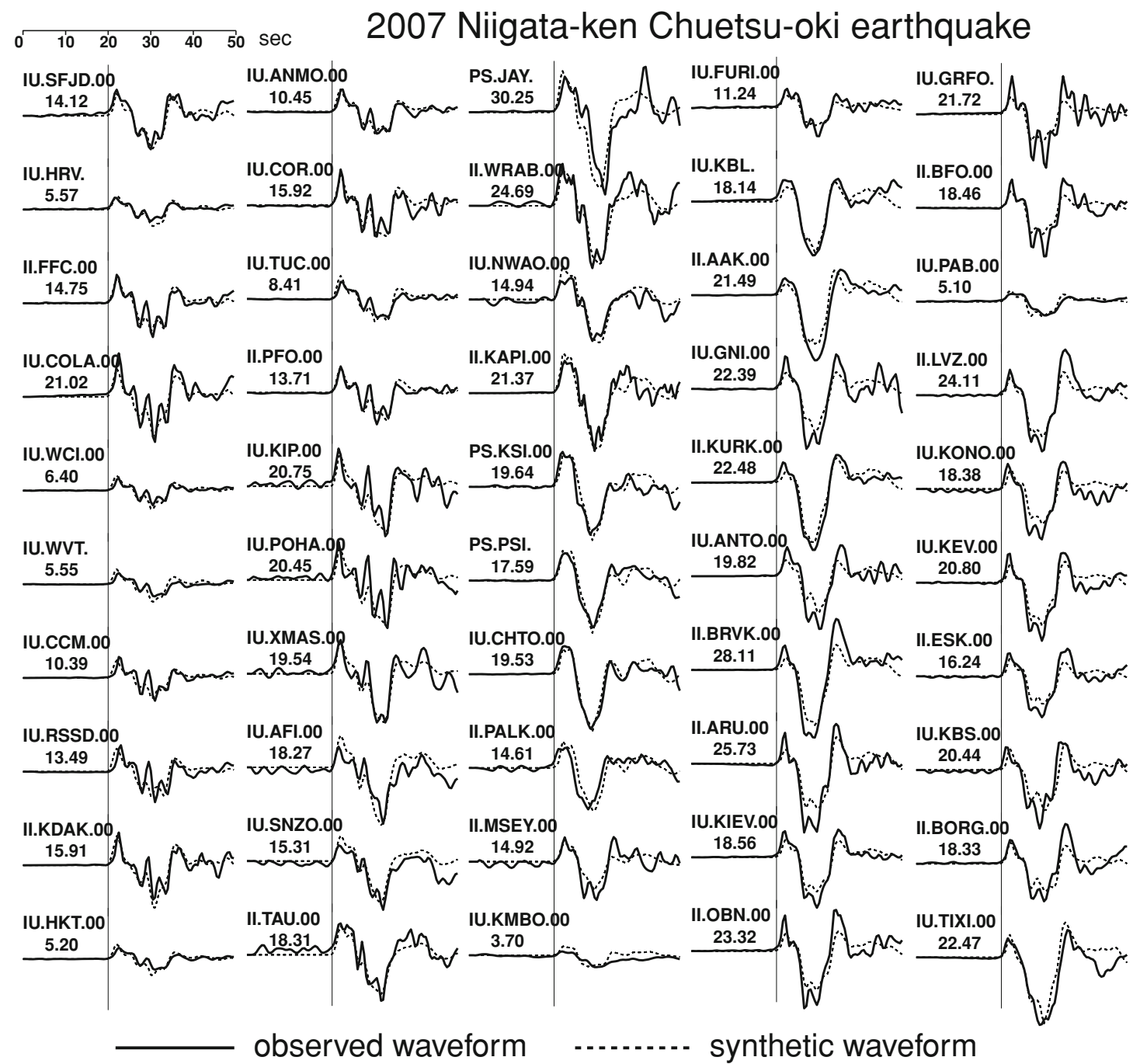

Fig. 3. Comparison of the observed (solid line) and synthetic (dashed line) waveforms. The number below the station code is the maximum amplitude of the observed waveform in micro-meter.

$30 \mathrm{GPa}$, we calculate maximum slips of $0.4 \mathrm{~m}$ and $1.6 \mathrm{~m}$ for the northwest- and southeast-dipping faults, respectively. We also calculate $7 \mathrm{~km}$ for the depth of the hypocenter using a grid search of minimum residual between observed and synthetic waveforms. We show the observed and the resultant synthetic waveforms in Fig. 3. The residual sum of squares between them is 0.238 .

We next calculate crustal deformation around the source area based on the elastic dislocation theory (Okada, 1985) and compare it with the observed crustal deformation to ver- 
(a)

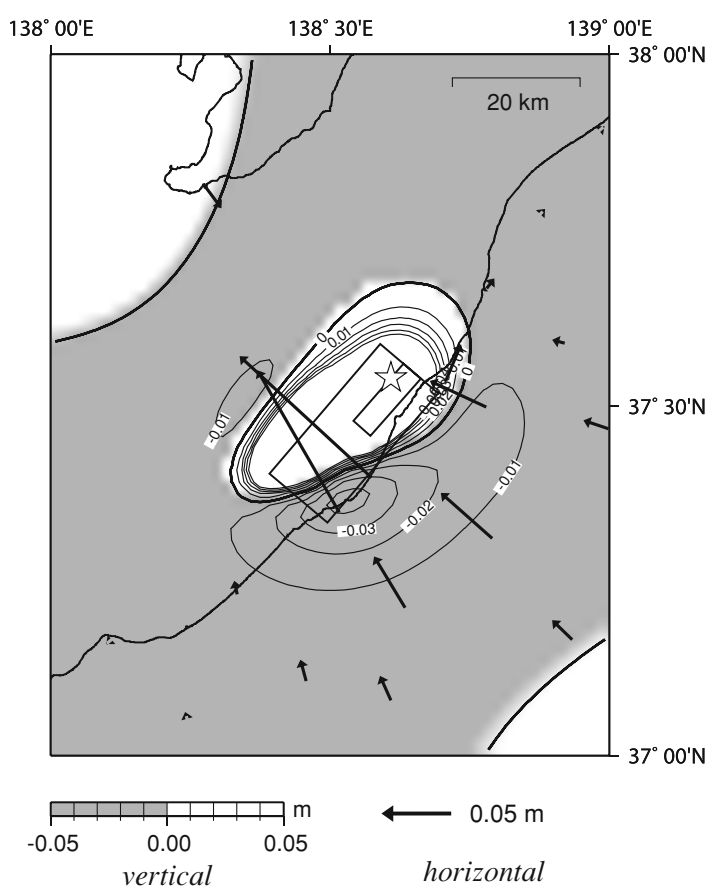

(b)

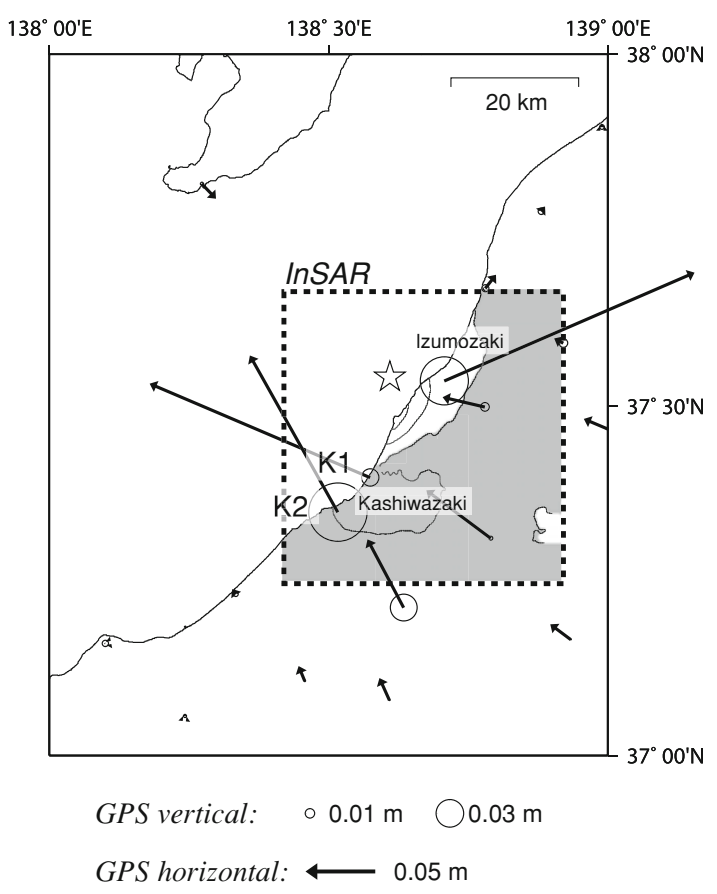

InSAR: $\quad \square$ up and east $\quad \square$ down and west

Fig. 4. Crustal deformation around the source area. (a) The vertical (contours) and horizontal (vectors) crustal deformations computed from elastic dislocation theory using the inversion results (Fig. 2). The down-dip vertical displacement is shaded and the contours are drawn with the interval of $0.01 \mathrm{~m}$. The thick line indicates $0.0 \mathrm{~m}$. (b) The observed crustal deformations by GPS and InSAR. For InSAR data, only the results from descending orbits around the hypocenter (dashed line) are shown. The circle indicates the vertical displacement measured from GPS data. K1 and K2 are the GPS locations in Kashiwazaki. We do not use the data in Izumozaki because of anomalous deformation caused by local site effects.

ify our results. Figure 4 shows the spatial distribution of the calculated crustal deformation compared to the vertical and horizontal deformation from GPS and descending InSAR data of the Geographical Survey Institute (GSI). The observed deformation pattern (Fig. 4(b)) shows the following features: (1) both up-dip and down-dip displacements are located around the source area; (2) the maximum horizontal and vertical displacements are observed in Kashiwazaki; (3) the vertical displacement and the direction of the horizontal component change abruptly within a distance of $10 \mathrm{~km}$ between two stations, K1 and K2, in Kashiwazaki. Although the geodetic deformation is not directly inverted, our estimated fault model by seismic source inversion explains the above features to a first-order approximation (Fig. 4(a)). We also test other simpler fault models with one northwestor southeast-dipping fault. The crustal deformation by the simpler models is systematically smaller than the observed value at GPS station around the source area, and the residual sum of squares for our conjugate model is better than that for the simpler models.

In summary, our inverse and forward modeling approaches indicate that the mainshock is associated with coseismic rupture along two faults oriented in a conjugate manner. The mainshock initiated rupture near the two northeastern ends of the northwest- and southeastdipping faults, releasing most of the seismic energy near their projected intersection (Figs. 1 and 2). The rupture propagated unilaterally southwestward, with the southeast- dipping fault releasing more seismic energy than the northwest-dipping fault (Fig. 2).

\section{Discussion and Conclusions \\ 4.1 Fault interaction}

We here discuss the cause of the complex rupture during the 2007 Chuetsu-oki earthquake and suggest two possible explanations. First, we suggest that Coulomb failure stress increases may have promoted rupture along the two faults. We calculate the Coulomb failure stress change in each subdivided fault segment due to faulting along the northwestand southeast-dipping faults assuming the apparent coefficient of friction of 0.4 (Fig. 5). We use the resultant slip direction as the fault geometry of the subdivided segment. In the case of the faulting in the southeast-dipping fault, most of the segment in the northwest-dipping fault just near the hypocenter is located by negative stress changes, while the positive changes are seen in the vicinity of the hypocenter. In the case of the faulting in the northwest-dipping fault, the segments in the southwestern region including the maximum slipped region and also the northeastern region in the vicinity of the hypocenter in the southeast-dipping fault are located in positive changes. Although the slip value and seismic moments in the northwest-dipping fault are small, the small fault size and its location produce the positive changes in both regions in the southeast-dipping fault. The stress changes in these regions exceed $0.01 \mathrm{MPa}$ (regions drawn by thick line in Fig. 5), which are compara- 

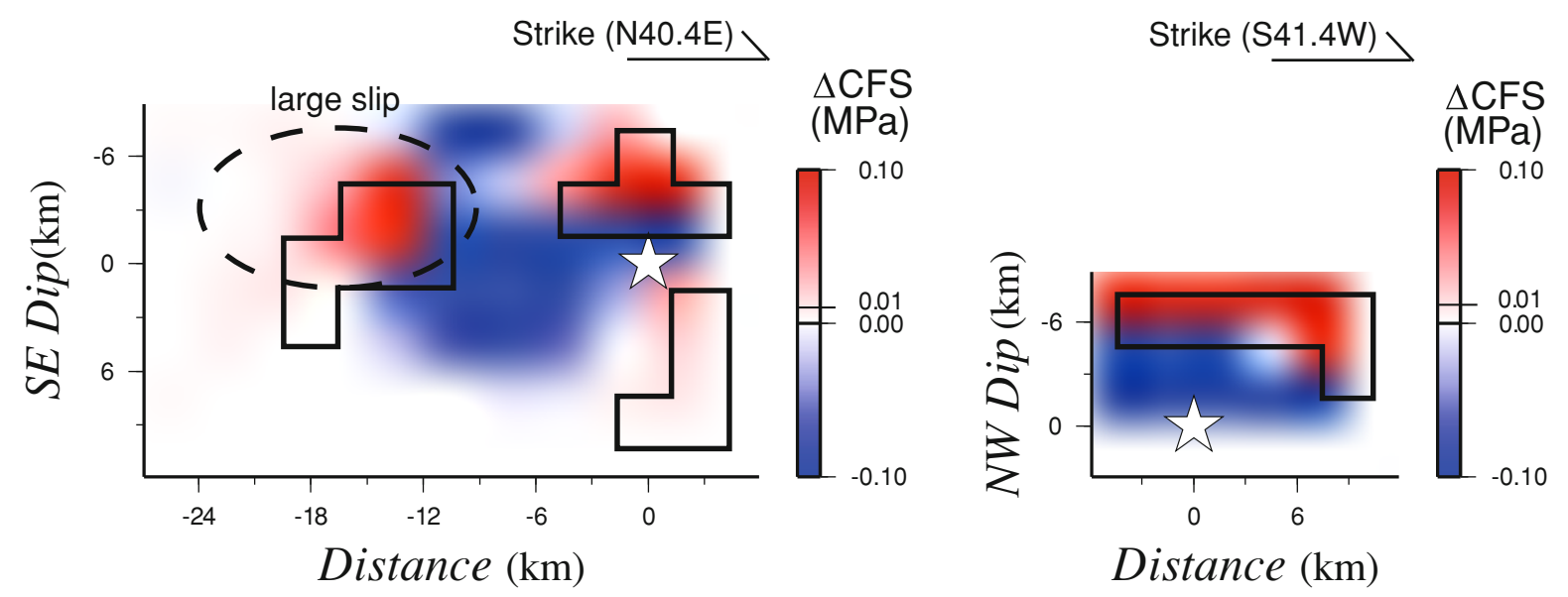

Fig. 5. Distribution of the Coulomb failure stress changes on the southeast- and northwest-dipping fault. Left and right panel shows the stress changes on the southeast-dipping fault induced by the faulting on the northwest-dipping fault and the changes on the northwest-dipping fault induced by the faulting on the southeast-dipping fault, respectively. The geometry of the receiver fault at each segment is based on the strike and the dip of its main fault and the resultant slip direction in the waveform inversion. The areas drawn by thick line show positive stress changes greater than $0.01 \mathrm{MPa}$. The large slipped region on the southeast-dipping fault is indicated by the broken-line ellipse.

ble to the minimum level affecting seismicity (e.g., Reasenberg and Simpson, 1992). Although we calculate the stress changes with other coefficient values, $0.2-0.8$, no significant differences are seen in our focus region. We conclude that the positive stress changes following the rupture along the northwest-dipping fault partially contributed to the large failure along the southeast-dipping fault.

\subsection{Crustal structure around the source region}

Second, we suggest that the complicated structures resulting from past faulting and heterogeneous physical properties of the surrounding crust may have contributed to rupture along the conjugate faults. Geological and bathymetric data show that the fold structure extends into the NKTZ and eastern margin of the Japan Sea, which is thought to be the result of the regional E-W compressive stress field for the last 3 million years. Based on seismic reflection surveys in a region adjacent to the source region, No et al. (2008) found strong reflective boundaries dipping both northwest and southeast. Although their seismic lines do not include the region near the hypocenter, the reflective boundaries are likely to continue into the source region. Our results may imply that the mainshock is associated slip along two faults consistent with the orientations of the reflective boundaries.

The seismic tomography results have shown the strong heterogeneity of velocity structures related with the existence of fluids derived from the Pacific slab (Nakajima and Hasegawa, 2007). The involvement of fluids in the fault zone has been supposed to be an important part on the process of faulting and seismicity (Hickman et al., 1995). Based on the results of these studies in this area, we suppose that complicated structures in property and geometry around the source region are the predominant cause for generating the complexity of coseismic fault system. In this area, the seismicity in the source region of the 2004 Chuetsu earthquake also showed the similar faulting pattern as the 2007 earthquake and indicated the presence of strong heterogeneous structures in and around the source region (e.g., Shibutani et al., 2005). A detailed study on dynamic ruptures and seismogenic structures of the 2007 earthquake may develop our understanding of the mechanics of this complex fault system.

Acknowledgments. We appreciate the constructive comments of editor Kiyoshi Yomogida, and reviewers Suzette J. Payne and Yuko Kase. We are also grateful to Takane Hori, Tetsuo No, Narumi Takahashi, Shuichi Kodaira, Keisuke Ariyoshi, Hiroshi Takenaka, Yosuke Yamamoto, Toshitaka Baba, Mikiya Yamashita, and Takeshi Sato for valuable discussions and suggestions. Yohei Yukutake and Tetsuya Takeda kindly provided us with results of hypocenter distribution. Original GPS and satellite data are distributed by the Geographical Survey Institute (GSI) and the Japan Aerospace Exploration Agency (JAXA), respectively. We used seismic data provided by IRIS and used seismic data of OHP provided by the Institute for Frontier Research on Earth Evolution (IFREE), the Japan Agency for Marine-Earth Science and Technology (JAMSTEC).

\section{References}

Bernard, P. and A. Zollo, The Irpinia (Italy) 1980 earthquake: Detailed analysis of a complex normal faulting, J. Geophys. Res, 94, 1631-1647, 1989.

Bowman, J. R., Geodetic evidence for conjugate faulting during the 1988 Tennant Creek, Australia earthquake sequence, Geophys. J. Int., 107, 47-56, 1991.

Bowman, J. R., G. Gibson, and T. Jones, Aftershocks of the 1988 January 22 Tennant Creek, Australia intraplate earthquakes: Evidence for a complex thrust fault geometry, Geophys. J. Int., 100, 87-97, 1990.

Choy, G. L. and J. R. Bowman, Rupture process of a multiple main shock sequence: Analysis of teleseismic, local, and field observations of the Tennant Creek, Australia, earthquakes of January 22, 1998, J. Geophys. Res., 95, 6867-6882, 1990.

Choy, G. L., J. Boatwright, J. W. Dewey, and S. A. Sipkin, A teleseismic analysis of the New Brunswick earthquake of January 9, 1982, J. Geophys. Res., 88, 2199-2212, 1983.

Hickman, S., R. Sibson, and R. Bruhn, Introduction to special section: Mechanical involvement of fluids in faulting, J. Geophys. Res., 100, 12831-12840, 1995.

Kikuchi, M. and H. Kanamori, Inversion of complex body waves-III, Bull. Seismol. Soc. Am., 81, 2335-2350, 1991.

Kikuchi, M. and H. Kanamori, Note on Teleseismic Body-Wave Inversion Program, http://www.eri.u-tokyo.ac.jp/ETAL/KIKUCHI/, 2003.

Langer, C. J., G. A. Bollinger, and H. M. Merghelani, Aftershocks of the 13 December 1982 North Yemen earthquake: Conjugate normal faulting in an extensional setting, Bull. Seismol. Soc. Am., 77, 2038-2055, 1987.

Lawson, C. L. and R. J. Hanson, Solving Least Squares Problems, 340 pp., Prentice-Hall, New Jersey, 1974. 
Miyamachi, H., K. Iwakiri, H. Yakiwara, K. Goto, and T. Kakuta, Fine structure of aftershock distribution of the 1997 Northwestern Kagoshima Earthquakes with a three-dimensional velocity model, Earth Planets Space, 51, 233-246, 1999.

Nakajima, J. and A. Hasegawa, Deep crustal structure along the NiigataKobe Tectonic Zone, Japan: Its origin and segmentation, Earth Planets Space, 59, e5-e8, 2007.

No, T., N. Takahashi, S. Kodaira, K. Takizawa, and Y. Kaneda, Deformation structure off Niigata observed by seismic reflection data, 2008 Jpn. Geosci. Union Meet., T229-P002, 2008.

Okada, Y., Surface deformation due to shear and tensile faults in a halfspace, Bull. Seismol. Soc. Am., 75, 1135-1154, 1985.

Payne, S. J., J. E. Zollweg, and D. W. Rodgers, Stress triggering of conjugate normal faulting: Late aftershocks of the $1983 M_{\mathrm{s}} 7.3$ Borah Peak, Idaho, earthquake, Bull. Seismol. Soc. Am., 94, 828-844, 2004.

Qamar, A. and J. Zollweg, The 1990 Deming, Washington earthquakes: A sequence of shallow thrust earthquakes in the Pacific Northwest, EOS Trans. AGU, 71, 1145, 1990

Reasenberg, P. A. and R. W. Simpson, Response of regional seismicity to the static stress change produced by the Loma Prieta earthquake, Science, 255, 1687-1690, 1992.

Sagiya, T., S. Miyazaki, and T. Tada, Continuous GPS array and presentday crustal deformation of Japan, Pure Appl. Geophys., 157, 2303-
2322, 2000

Sakai, S., N. Hirata, A. Kato, E. Kurashimo, T. Iwasaki, and T. Kanazawa, Multi-fault system of the 2004 Mid-Niigata Prefecture Earthquake and its aftershocks, Earth Planets Space, 57, 417-422, 2005.

Shibutani, T., Y. Iio, S. Matsumoto, H. Katao, T. Matsushima, S. Ohmi, F. Takeuchi, K. Uehira, K. Nishigami, B. Enescu, I. Hirose, Y. Kano, Y. Kohno, M. Korenaga, Y. Mamada, M. Miyazawa, K. Tatsumi, T. Ueno, H. Wada, and Y. Yukutake, Aftershock distribution of the 2004 Mid Niigata Prefecture Earthquake derived from a combined analysis of temporary online observations and permanent observations, Earth Planets Space, 57, 545-549, 2005.

Wetmiller, R. J., J. Adams, F. M. Anglin, H. S. Hasegawa, and A. E. Stevens, Aftershock sequences of the 1982 Miramichi, New Brunswick, earthquakes, Bull. Seismol. Soc. Am., 74, 621-653, 1984.

Yukutake, Y., T. Takeda, and K. Obara, Well-resolved hypocenter distribution using the double-difference relocation method in the region of the 2007 Chuetsu-oki Earthquake, Earth Planets Space, 60, 1105-1109, 2008.

T. Nakamura (e-mail: t_nakamura@jamstec.go.jp), Y. Ishihara, Y. Yamanaka, and Y. Kaneda 